\title{
CRESCIMENTO E PRODUTIVIDADE DE CULTIVARES DE MORANGUEIRO DE “DIA NEUTRO” EM DIFERENTES DENSIDADES DE PLANTIO EM SISTEMA DE CULTIVO ORGÂNICO (')
}

\author{
ANDRÉ SAMUEL STRASSBURGER $(2,3 *)$; ROBERTA MARINS NOGUEIRA PEIL $\left({ }^{2}\right)$; \\ JOSÉ ERNANI SCHWENGBER ( ${ }^{(3)}$; CARLOS ALBERTO BARBOSA MEDEIROS $\left({ }^{3}\right)$; \\ DENISE DE SOUZA MARTINS $(2,3)$; JURANDIR BUCHWEITZ E SILVA $(2,3)$
}

\begin{abstract}
RESUMO
Realizou-se um experimento com o objetivo de avaliar o efeito da densidade de plantio sobre o crescimento e a produtividade de duas cultivares de morangueiro de "dia neutro" em sistema de cultivo orgânico. O experimento foi realizado em Pelotas (RS). Os tratamentos constaram da combinação de dois fatores experimentais: densidade de plantio $\left(3,51 ; 5,26\right.$ e 7,02 plantas $\mathrm{m}^{-2}$ correspondentes a linhas duplas, triplas e quádruplas, respectivamente) e cultivar (Diamante e Aromas). O delineamento experimental adotado foi o de blocos completos casualizados com quatro repetições. No fim do período experimental, foram determinadas a produção e a partição de biomassa dos órgãos aéreos das plantas, a produtividade e os principais índices de crescimento. $\mathrm{O}$ cultivo do morangueiro na densidade de 5,26 plantas $\mathrm{m}^{-2}$ (em linhas triplas) proporciona adequada produção e partição de biomassa das plantas e produtividade de frutos de 30,4 $\mathrm{Mg} \mathrm{ha}^{-1}$, valor superior a densidade de 3,51 plantas $\mathrm{m}^{-2}$ (linhas duplas) e semelhante ao da densidade de 7,02 plantas $\mathrm{m}^{-2}$ (linhas quádruplas). Assim, a adoção de linhas triplas de cultivo pode ser empregada para favorecer o crescimento das plantas e a produtividade da cultura em sistema orgânico de produção. As cultivares Diamante e Aromas proporcionaram padrões semelhantes de crescimento e de produtividade.
\end{abstract}

Palavras-chave: Fragaria $x$ ananassa Duch., fisiologia da produção, produção e partição de massa seca, produção sustentável, manejo ecológico.

\author{
ABSTRACT \\ GROWTH AND YIELD OF “DAY-NEUTRAL” STRAWBERRY CULTIVARS \\ IN DIFFERENT PLANT DENSITIES IN ORGANIC CROP SYSTEM
}

\begin{abstract}
The aim of this work was to evaluate the effect of plant density on growth and yield of two "day-neutral" strawberry cultivars in organic crop system. The experiment was carried out in Pelotas, Rio Grande do Sul State. The treatments were composed by the combination of two experimental factors: plant density (3.51; 5.26 and 7.02 plants $\mathrm{m}^{-2}$, corresponding to double, triple and quadruple rows, respectively) and cultivars (Diamante and Aromas). The experimental design was in randomized blocks with four replications. At the end of the experiment, dry mass production and partitioning, yield and the main growth index were evaluated. The strawberry crop at 5.26 plants $\mathrm{m}^{-2}$ (triple row) provide an appropriate plant biomass production and partitioning and a yield of $30.4 \mathrm{Mg}^{-1}$. This yield was higher than the yield obtained at 3.51 plants $\mathrm{m}^{-2}$ (double row) and similar to the values found in the treatment with 7.02 plants $\mathrm{m}^{-2}$ (quadruple row). Therefore, triple row arrangement for strawberry crop can be used in order to benefit plant growth and yield in organic crop system. The Diamante and Aromas cultivars showed similar growth and yield pattern.
\end{abstract}

Key words: Fragaria $x$ ananassa Duch., crop production physiology, dry mass production and partitioning, sustainable production, ecological management.

(1) Recebido para publicação em 5 de novembro de 2009 e aceito em 18 de fevereiro de 2010.

(2) Universidade Federal de Pelotas, Faculdade de Agronomia Eliseu Maciel, Departamento de Fitotecnia. Campus Universitário s/n, Caixa-Postal 354, 96010-900 Pelotas (RS). E-mail: strassburger.as@gmail.com (*) Autor Correspondente.

( ${ }^{3}$ Empresa Brasileira de Pesquisa Agropecuária, Centro de Pesquisa Agropecuária de Clima Temperado, Estação Experimental Cascata, Caixa-Postal 403, 96001-970 Pelotas (RS). 


\section{INTRODUÇÃO}

No Brasil, atualmente, a produção de morangos é em grande parte dominada pelo uso de cultivares de morangueiro de "dia curto". Estas cultivares, em condições de temperaturas elevadas e de dias longos, têm maior crescimento vegetativo em detrimento do reprodutivo. Dessa forma, a partir de novembro até o início do inverno, observa-se menor oferta da fruta no mercado. Em contrapartida, nesse período de escassez de morangos, é que há maior valor de mercado. Este fato justifica a crescente busca por cultivares de "dia neutro" que proporcionem maior produção durante os períodos mais quentes do ano, uma vez que possuem menor sensibilidade aos estímulos que o fotoperíodo e a temperatura exercem sobre a emissão de estolões e, consequentemente, prorrogam o período de frutificação.

De forma geral, os programas de melhoramento genético do morangueiro caracterizam-se pela avaliação e seleção de clones em sistema de cultivo convencional. Assim, as cultivares provenientes desses programas podem proporcionar menor produtividade e qualidade de produção em sistemas de cultivo orgânico (CASTRO et al., 2003), uma vez que as características produtivas das cultivares resultam do manejo adotado e das condições ambientais a que são submetidas, sendo necessária a adequação do manejo e da cultivar a ser utilizada com o ambiente de cultivo (DuARTE FILHO et al., 2007).

Além das próprias características genéticas das cultivares, algumas práticas de manejo, como a variação da densidade de plantio, podem interferir no crescimento das plantas (MARCElis et al., 1998; Peil e GÁlVEZ, 2002; 2005; DUARTE et al., 2008), que pode ser definido como a produção e a partição de biomassa (massa fresca e seca) entre os diferentes órgãos das plantas (MARCELIS et al., 1998).

A densidade de plantio afeta a penetração da radiação solar no dossel vegetal, a taxa fotossintética e o equilíbrio entre o crescimento da fração vegetativa e dos frutos. O emprego de uma densidade de plantio adequada proporciona maior eficiência da utilização da radiaçãosolar incidente sobreo dossel e a maior produção por área. Um comportamento típico de qualquer espécie cultivada é o aumento da produtividade até certa densidade. Posteriormente, atinge-se um limite, a partir do qual, as plantas competem fortemente por fatores essenciais de crescimento, como nutrientes, luz e água. Assim, o crescimento individual das plantas é negativamente afetado, a ponto de haver prejuízos à produtividade da cultura.

Vários trabalhos já foram realizados buscando avaliar o crescimento de algumas hortaliças de fruto em função da densidade de plantio (PAPAdopoulos e ORMrod, 1991; Peil e GÁlvez, 2002 e 2005; Duarte et al., 2008). Para a cultura do morangueiro, existem trabalhos relacionados a esse tema, todavia, abordam aspectos relacionados à produtividade (ALBREGTS, 1971; Albregts e Howard, 1973; FreEMAN, 1981, DiJKSTRA et al., 1993; LiNSLEY-NOAKES et al., 2006) e à incidência de doenças (MAdDEn e Boudreau, 1997; Legard et al., 2000. Informações mais aprofundadas sobre o crescimento do morangueiro são escassas e, em se tratando de cultivares de "dia neutro" e de densidade de plantio em sistema de cultivo orgânico, são inexistentes.

Dessa forma, o objetivo deste trabalho foi avaliar o crescimento de cultivares de morangueiro de "dia neutro" em sistema de cultivo orgânico, observando a influência de diferentes densidades de plantio sobre a produção acumulada de biomassa e a partição de massa seca entre os órgãos aéreos das plantas, bem como sobre os principais índices de crescimento e a produtividade da cultura, a fim de definir o número de linhas simples a ser adotado na lavoura.

\section{MATERIAL E MÉTODOS}

O experimento foi realizado no município de Pelotas (RS). A localização geográfica aproximada é de: $31^{\circ} 37^{\prime} \mathrm{S}, 52^{\circ} 31^{\prime} \mathrm{W}$ e altitude de $181 \mathrm{~m}$. A classificação do clima da região, conforme W. Köppen é do tipo "cfa" - clima temperado, com chuvas bem distribuídas ao longo do ano e verões quentes (MотA et al., 1986).

$\mathrm{O}$ experimento foi realizado em canteiros, abrigados por túneis baixos cobertos com filme de polietileno de baixa densidade (PEBD) transparente com $100 \mu \mathrm{m}$ de espessura, dispostos no sentido LesteOeste. O controle do aumento excessivo da temperatura, bem como a renovação do ar no interior dos túneis, foi realizado por meio do soerguimento lateral do plástico de revestimento nas primeiras horas da manhã e seu fechamento ao entardecer. Em dias de chuvas e ventos fortes, foram mantidos parcial ou totalmente fechados, dependendo das condições climáticas predominantes.

Os canteiros foram preparados com enxada rotativa encanteiradora, construindo-se canteiros com aproximadamente $0,3 \mathrm{~m}$ de altura. Foram utilizados quatro canteiros, com dimensões de 1,1 x 10,0 m com passeios de $0,5 \mathrm{~m}$. A correção do solo foi realizada conforme o resultado da análise química do solo, levando-se em consideração as recomendações segundo a COMISSÃO DE Qú́MICA E FERTILIDADE DO SOLO (2004) para a cultura do morangueiro, com base na concentração de potássio no solo.

Para a correção do $\mathrm{pH}$ foram aplicados $2,7 \mathrm{Mg}$ ha-1 de calcário dolomítico, com PRNT de 98\%. Para a correção da fertilidade do solo, foram utilizados $18,6 \mathrm{Mg} \mathrm{ha}^{-1}$ de vermicomposto bovino e $24,0 \mathrm{Mg}$ $\mathrm{ha}^{-1}$ de torta de mamona. Posteriormente, a enxada rotativa encanteiradora foi novamente utilizada para a incorporação do calcário e dos fertilizantes. 
O transplante das mudas foi realizado em 4/7/2008. A irrigação das plantas foi realizada por gotejamento, sendo sua necessidade monitorada pelo método da tensão da água no solo com o auxílio de tensiômetro de vacuômetro instalados a 0,15 m de profundidade, mantendo-se o solo próximo à capacidade de campo (0,01 a 0,03 MPa), segundo recomendações de PIREs et al. (2006). A fertirrigação foi realizada utilizandose húmus líquido a $10 \%$, preparado de acordo com a recomendação de SCHIEDECK et al. (2006).

Para cobertura dos canteiros foi utilizado plástico preto (PEBD) com $50 \mu \mathrm{m}$ de espessura e 2,0 m de largura, colocado sobre os canteiros 30 dias após o transplante das mudas. O controle de pragas e de doenças foi realizado utilizando-se calda bordalesa, calda sulfocálcica, extrato de "Neem" e alhol (mistura de alho triturado, óleo vegetal, sabão neutro e água). Ainda, como forma de prevenção e redução da fonte de inóculo, foram realizadas limpezas frequentes nas plantas, retirando-se folhas, frutos ou até mesmo plantas severamente atacadas por pragas ou doenças.

Os tratamentos experimentais constaram da combinação de dois fatores experimentais: densidade de plantio e cultivar. O primeiro fator foi estudado em três diferentes níveis: 3,51; 5,26 e 7,02 plantas $\mathrm{m}^{-2}$, levandose em consideração a área total utilizada (incluindo os passeios), determinada pelo número de linhas simples utilizadas por canteiros, respectivamente 2; 3 e 4 (cultivo em linhas duplas, triplas ou quádruplas), uma vez que o espaçamento adotado foi de $0,30 \times 0,30 \mathrm{~m}$. O fator cultivar foi estudado em dois níveis: Diamante e Aromas, ambas classificadas como indiferentes ao fotoperíodo ou de "dia neutro" e provenientes de viveiros chilenos.

O delineamento experimental adotado foi o de blocos completos casualizados, com quatro repetições, sendo a unidade experimental composta por 10, 15 e 20 plantas nas densidades de 3,51; 5,26 e 7,02 plantas $\mathrm{m}^{-2}$. Posteriormente ao transplante, foi selecionada uma planta por repetição, sobre a qual se manteve total controle da colheita, da remoção de folhas e de estolões durante o período de cultivo. A necessidade deste rigoroso controle diário durante um longo período determinou a utilização de apenas uma planta controle por repetição. Nos tratamentos com densidade de 5,26 e 7,02 plantas $\mathrm{m}^{-2}$, as plantas-controle foram selecionadas nas linhas centrais do canteiro. O crescimento da cultura foi quantificado por meio da determinação da biomassa aérea acumulada das plantas-controle aos 186 dias após o transplante $(7 / 1 / 2009)$, sendo incluídos os frutos colhidos durante o processo produtivo, bem como as folhas provenientes de desfolhas antecipadas e os estolões removidos. As plantas foram separadas em três frações: folha (incluindo pecíolos), coroa (incluindo os estolões) e frutos. A massa seca total da parte aérea da planta correspondeu à soma das folhas, coroa e frutos e a massa seca vegetativa à soma das folhas e coroa.

Cada fração foi pesada, para a obtenção da massa fresca, e seca, em estufa de ventilação forçada a $65{ }^{\circ} \mathrm{C}$ até massa constante, para a obtenção da massa seca. Determinou-se, também, a área foliar acumulada no fim do experimento com um integrador de área foliar (LI-COR, modelo 3100). A partir dos dados de massa fresca e seca dos órgãos aéreos das plantas e da área foliar, calculou-se a produtividade, a partição de massa seca entre os órgãos aéreos das plantas e os índices de crescimentodeinteresse. Os resultadosforamsubmetidos à análise de variância e as médias comparadas pelo teste DMS de Fisher a 5\% de probabilidade de erro.

\section{RESULTADOS E DISCUSSÃO}

$\mathrm{O}$ crescimento, representado pela produção de massa fresca e seca (Tabelas 1 e 2) e pela partição de massa seca entre os diferentes órgãos das plantas (Tabela 3), assim como o índice de área foliar e a razão de área foliar, foram influenciados pela densidade de plantio.

As plantas cultivadas na maior densidade $(7,02$ plantas $\mathrm{m}^{-2}$ ) proporcionaram maior produção de massa fresca das folhas em relação à densidade intermediária $\left(5,26\right.$ plantas $\mathrm{m}^{-2}$; Tabela 1$)$, não diferindo da densidade mais baixa $\left(3,51\right.$ plantas $\left.\mathrm{m}^{-2}\right)$. Em relação à massa seca das folhas (Tabela 2), com maior densidade houve superioridade em relação às demais, e na densidade intermediária notou-se o menor valor. As massas fresca e seca da coroa não foram influenciadas pela densidade de plantio (Tabelas 1 e 2). Dessa forma, a massa fresca da fração vegetativa das plantas na densidade intermediária foi inferior a da maior densidadee, em relaçãoà massa seca, inferior às outras duas densidades de plantio. Entretanto, quando se observa a produção de massa fresca de frutos por planta (Tabela 1), verifica-se que a maior densidade de plantio causou redução no valor desta variável, o que levou à menor produção de massa fresca do total da parte aérea e menor índice de colheita, não sendo observadas diferenças entre as densidades de 3,51 e 5,26 plantas $\mathrm{m}^{-2}$ em relação a estas três variáveis. Quanto à produção de massa seca de frutos (Tabela 2) a resposta foi semelhante, posto que houve decréscimo significativo de valores já quando se aumentou a densidade de 3,51 para 5,26 plantas $\mathrm{m}^{-2}$, o que levou à redução da massa seca do total da parte aérea das plantas nas duas maiores densidades de plantio (Tabela 2).

A maior densidade de plantio reduziu a contribuição proporcional da massa seca de frutos para a composição do total da planta, beneficiando a alocação de massa seca para a fração vegetativa (Tabela 3). As folhas representaram a maior fração dos órgãos vegetativos aéreos, e, na maior densidade de plantio, 
Tabela 1. Produção de massa fresca dos órgãos aéreos, produtividade (Prod.) e índice de colheita (IC) de plantas de morangueiro de acordo com a densidade de plantio e a cultivar em sistema de cultivo orgânico. Embrapa Clima Temperado, Pelotas, 2009

\begin{tabular}{|c|c|c|c|c|c|c|c|}
\hline \multirow[b]{2}{*}{ Densidade } & \multicolumn{7}{|c|}{ Produção de massa fresca } \\
\hline & Folhas & Coroa $\left({ }^{1}\right)$ & $\begin{array}{c}\text { Fração } \\
\text { Vegetativa }\left({ }^{2}\right)\end{array}$ & Frutos & Total $\left({ }^{3}\right)$ & Prod. & $\mathrm{IC}\left({ }^{4}\right)$ \\
\hline plantas $\mathrm{m}^{-2}$ & & & - g planta ${ }^{-1}$ & & - & $\mathrm{Mg} \mathrm{ha}^{-1}$ & \\
\hline 3,51 & $160,56 \mathrm{ab}\left(^{5}\right)$ & 74,36 a & $234,92 \mathrm{ab}$ & $531,73 \mathrm{a}$ & $766,64 \mathrm{a}$ & $18,66 \mathrm{~b}$ & $0,69 \mathrm{a}$ \\
\hline 5,26 & $138,06 \mathrm{~b}$ & 64,89 a & $202,95 \mathrm{~b}$ & $577,43 \mathrm{a}$ & $780,38 \mathrm{a}$ & $30,37 \mathrm{a}$ & $0,74 \mathrm{a}$ \\
\hline 7,02 & $173,65 \mathrm{a}$ & 70,29 a & $243,94 \mathrm{a}$ & $411,42 \mathrm{~b}$ & $655,36 \mathrm{~b}$ & $28,88 \mathrm{a}$ & $0,62 \mathrm{~b}$ \\
\hline \multicolumn{8}{|l|}{ Cultivar } \\
\hline Diamante & $161,77 \mathrm{a}^{(6)}$ & 76,09 a & $237,86 \mathrm{a}$ & $536,02 \mathrm{a}$ & $773,89 \mathrm{a}$ & $27,82 \mathrm{a}$ & $0,69 \mathrm{a}$ \\
\hline Aromas & 153,08 a & $63,60 \mathrm{~b}$ & $216,68 \mathrm{a}$ & $477,69 \mathrm{a}$ & $694,37 \mathrm{~b}$ & $24,12 \mathrm{a}$ & $0,67 \mathrm{a}$ \\
\hline $\mathrm{CV}$ & 15,97 & 20,81 & 13,62 & 19,98 & 14,14 & 18,11 & 7,52 \\
\hline
\end{tabular}

$\left({ }^{1}\right)$ Coroa corresponde a soma da coroa + estolões + pedúnculo. $\left({ }^{2}\right)$ Fração vegetativa corresponde à soma: folhas + coroa. $\left({ }^{3}\right)$ Total da planta corresponde à soma fração vegetativa + frutos. $\left({ }^{4}\right)$ Razão entre massa fresca de frutos e a massa fresca total de parte aérea. ${ }^{5}$ ) Médias seguidas da mesma letra para densidade não diferem entre si pelo teste DMS de Fisher a 5\% de probabilidade de erro. $\left(^{6}\right)$ Médias seguidas da mesma letra para cultivares não diferem entre si pelo teste $\mathrm{F}$ a $5 \%$ de probabilidade de erro.

Tabela 2. Produção de massa seca dos órgãos aéreos de plantas de morangueiro de acordo com a densidade de plantio e a cultivar em sistema de cultivo orgânico. Embrapa Clima Temperado, Pelotas, 2009

\begin{tabular}{|c|c|c|c|c|c|}
\hline \multirow{2}{*}{ Densidade } & \multicolumn{5}{|c|}{ Produção de massa seca } \\
\hline & Folhas & Coroa $\left(^{1}\right)$ & Fração Vegetativa $\left({ }^{2}\right)$ & Frutos & Total $\left({ }^{3}\right)$ \\
\hline plantas $\mathrm{m}^{-2}$ & & 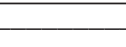 & - g planta ${ }^{-1}$ & & \\
\hline 3,51 & $49,29 \mathrm{~b}\left({ }^{4}\right)$ & $20,64 \mathrm{a}$ & $69,93 \mathrm{a}$ & 56,41 a & $126,34 \mathrm{a}$ \\
\hline 5,26 & $40,25 \mathrm{c}$ & $18,03 \mathrm{a}$ & $58,28 \mathrm{~b}$ & $43,70 \mathrm{~b}$ & $101,98 \mathrm{~b}$ \\
\hline 7,02 & $55,03 \mathrm{a}$ & $19,18 \mathrm{a}$ & $74,22 \mathrm{a}$ & $29,69 \mathrm{c}$ & $103,91 \mathrm{~b}$ \\
\hline \multicolumn{6}{|l|}{ Cultivar } \\
\hline Diamante & 47,85 a $\left(^{5}\right)$ & $20,19 \mathrm{a}$ & $68,04 \mathrm{a}$ & $43,83 \mathrm{a}$ & $111,86 \mathrm{a}$ \\
\hline Aromas & $48,53 \mathrm{a}$ & $18,38 \mathrm{a}$ & $66,91 \mathrm{a}$ & $42,71 \mathrm{a}$ & $109,62 \mathrm{a}$ \\
\hline $\mathrm{CV}$ & 10,67 & 15,84 & 7,51 & 15,11 & 6,86 \\
\hline
\end{tabular}

$\left({ }^{1}\right)$ Coroa corresponde à soma da coroa + estolões + pedúnculo. $\left({ }^{2}\right)$ Fração vegetativa corresponde à soma: folhas + coroa. $\left({ }^{3}\right)$ Total da parte aérea da planta corresponde à soma fração vegetativa + frutos. $\left({ }^{4}\right)$ Médias seguidas da mesma letra para densidade não diferem entre si pelo teste DMS de Fisher a 5\% de probabilidade de erro. $\left(^{5}\right)$ Médias seguidas da mesma letra para cultivares não diferem entre si pelo teste $\mathrm{F}$ a $5 \%$ de probabilidade de erro.

houve uma redução da contribuição proporcional da coroa para a composição total da fração vegetativa em relação às densidades mais baixas. $\mathrm{O}$ índice de área foliar e a razão de área foliar foram superiores na maior densidade e a área foliar específica não foi influenciada pela densidade de plantio (Tabela 3).

Em relação ao efeito do fator cultivar, Diamante e Aromas demonstraram padrões de produção e de partição de massa fresca e seca e produtividade semelhantes: observou-se maior produção de massa fresca da coroa e do total das plantas em 'Diamante' e a área foliar específica e a razão de área foliar foram superiores em 'Aromas' (Tabela 3).

'Diamante' proporcionou menor área foliar específica e menor razão de área foliar, demonstrando maior espessura de limbo e maior eficiência fotossintética (dada pela menor razão de área foliar, uma vez que houve maior produção de massa seca aérea por unidade de área foliar), o que, no entanto, não foi suficiente para interferir no crescimento e na produtividade das plantas.

Apesar da maior densidade de plantio ter reduzido a produção de massa fresca de frutos por planta, o aumento do número de plantas por unidade de área levou a que a produtividade da densidade de 7,02 plantas $\mathrm{m}^{-2}$ fosse semelhante à da densidade intermediária e superasse a da densidade de 3,51 plantas $\mathrm{m}^{-2}$ (Tabela 1). O aumento da densidade de plantio geralmente reduz a produção individual das plantas, no entanto, o incremento do número de plantas por unidade de área compensa a redução individual da produção até uma determinada população de plantas (PEREIRA, 1989). O aumento da densidade de 5,26 para 7,02 plantas $\mathrm{m}^{-2}$ provocou uma redução da produção por planta de tal 
Tabela 3. Partição proporcional de massa seca entre os órgãos aéreos, índice de área foliar (IAF), área foliar específico (AFE) e razão de área foliar (RAF) de plantas de morangueiro de acordo com a densidade de plantio e a cultivar em sistema de cultivo orgânico. Embrapa Clima Temperado, Pelotas, 2009

\begin{tabular}{|c|c|c|c|c|c|c|c|}
\hline \multirow{3}{*}{ Densidade } & \multicolumn{4}{|c|}{ Relação de massa seca } & \multirow{3}{*}{$\operatorname{IAF}\left({ }^{4}\right)$} & \multirow{3}{*}{$\operatorname{AFE}\left({ }^{5}\right)$} & \multirow{3}{*}{$\operatorname{RAF}\left({ }^{6}\right)$} \\
\hline & \multicolumn{2}{|c|}{ Órgão/Planta } & \multicolumn{2}{|c|}{ Órgão/FV } & & & \\
\hline & Frutos & $\mathrm{FV}\left({ }^{2}\right)$ & Coroa $\left({ }^{3}\right)$ & Folhas & & & \\
\hline plantas $\mathrm{m}^{-2}$ & 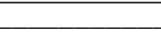 & 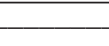 & & & $\mathrm{m}^{2} \mathrm{~m}^{-2}$ & $\mathrm{~cm}^{2} \mathrm{~g}^{-1}$ & $\mathrm{~cm}^{2} \mathrm{~g}^{-1}$ \\
\hline 3,51 & 0,45 a $\left(^{7}\right)$ & $0,55 \mathrm{~b}$ & $0,30 \mathrm{a}$ & $0,70 \mathrm{~b}$ & $1,50 \mathrm{~b}$ & $86,50 \mathrm{a}$ & $33,78 \mathrm{~b}$ \\
\hline 5,26 & $0,43 \mathrm{a}$ & $0,57 \mathrm{~b}$ & $0,31 \mathrm{a}$ & $0,69 \mathrm{~b}$ & $1,86 \mathrm{~b}$ & $87,62 \mathrm{a}$ & $34,69 \mathrm{~b}$ \\
\hline 7,02 & $0,29 \mathrm{~b}$ & $0,71 \mathrm{a}$ & $0,26 \mathrm{~b}$ & $0,74 \mathrm{a}$ & $3,25 \mathrm{a}$ & $85,02 \mathrm{a}$ & $44,62 \mathrm{a}$ \\
\hline \multicolumn{8}{|l|}{ Cultivar } \\
\hline Diamante & 0,39 a $\left({ }^{8}\right)$ & $0,61 \mathrm{a}$ & $0,30 \mathrm{a}$ & $0,70 \mathrm{a}$ & $2,07 \mathrm{a}$ & 82,43 b & $35,05 \mathrm{~b}$ \\
\hline Aromas & $0,38 \mathrm{a}$ & $0,62 \mathrm{a}$ & $0,28 \mathrm{a}$ & $0,72 \mathrm{a}$ & $2,34 \mathrm{a}$ & $90,32 \mathrm{a}$ & $40,34 \mathrm{a}$ \\
\hline $\mathrm{CV}(\%)$ & 11,36 & 7,16 & 13,96 & 5,63 & 16,08 & 9,85 & 11,00 \\
\hline
\end{tabular}

(1) Total da planta corresponde à soma fração vegetativa + frutos. $\left(^{2}\right) \mathrm{FV}$ : fração vegetativa corresponde à soma: folhas + coroa. $\left({ }^{3}\right)$ Coroa corresponde à soma da coroa + estolão + pedúnculo. $\left({ }^{4}\right)$ IAF corresponde à área foliar por unidade de área de solo. $\left({ }^{5}\right)$ AFE corresponde ao quociente entre a área foliar e a massa seca das folhas. $\left.{ }^{6}\right)$ RAF corresponde ao quociente entre a área foliar e a massa seca total das plantas. (7) Médias seguidas da mesma letra para densidade não diferem entre si pelo teste DMS de Fisher a 5\% de probabilidade de erro. $\left(^{8}\right)$ Médias seguidas da mesma letra para cultivares não diferem entre si pelo teste $\mathrm{F}$ a $5 \%$ de probabilidade de erro.

ordem, a ponto de que o aumento do número de plantas não resultasse em elevação da produção por área.

Os resultados observados em relação à produtividade estão de acordo com os relatados na bibliografia (ANDRIOLO et al., 2002; FERNANDES JúNIOR et al., 2002; CASTRO et al., 2003; ANDRIOLO et al., 2009; Loss et al., 2009), revelando que o sistema de cultivo orgânico proporciona produtividade semelhante a outros sistemas de produção já consagrados para a cultura do morangueiro. Ainda, é importante salientar que a massa média dos frutos não foi influenciada pelos fatores experimentais avaliados. No presente estudo, obteve-se média geral de 15,5 $\mathrm{g}$ fruto $^{-1}$. As principais dificuldades verificadas pelos agricultores para a produção de morangos fora da época tradicional de cultivo são a obtenção de produtividade adequada e a colheita de frutos com tamanho satisfatório. Nesse contexto, o valor obtido para a massa média dos frutos no presente trabalho, assemelha-se aos observados por outros autores em períodos de cultivo tradicionais com cultivares de dia curto (CONTI et al., 2002; CASTO et al., 2003; Villela Júnior et al., 2004; Virmond e RESENDE, 2006).

O índice de colheita foi inferior na densidade de 7,02 plantas $\mathrm{m}^{-2}$ (Tabela 1). Esse índice representa a eficiência de conversão de produtos sintetizados em material de importância econômica, sendo influenciado pelo genótipo e pelo ambiente (PEREIRA e MACHADO, 1987; BenincAsa, 2003). Assim, com a densidade de plantio de 7,02 plantas $\mathrm{m}^{-2}$ houve redução da capacidade de alocação de massa seca (Tabela 2) e fresca (Tabela 1) para os órgãos de interesse econômico, embora a produtividade das plantas nesta densidade de plantio tenha sido semelhante à da densidade intermediária.

Tem sido demonstrado na literatura que o manejo da densidade de plantio interfere na produção e partição da massa seca das plantas (PeIl e GÁlvez, 2002, DUARTE et al., 2008). Este fato normalmente se deve ao sombreamento mútuo e à interferência negativa que elevadas densidades de plantio exercem sobre a penetração da radiação solar no interior do dossel, reduzindo a quantidade dessa radiação interceptada individualmente pela planta e a taxa fotossintética e, consequentemente, a produção de massa seca das plantas. Portanto, não era esperado que a massa seca das folhas tivesse uma superioridade tão expressiva na maior densidade de plantio em relação às demais. Deve-se primeiramente considerar que, devido à arquitetura da planta de morangueiro, de porte baixo e com a disposição das folhas concentradas ao redor da coroa, a ocorrência de sombreamento mútuo somente vai ocorrer para valores muito elevados de densidade. Outro fator importante é que nesta pesquisa, para as três densidades estudadas, adotou-se o mesmo espaçamento entre as linhas simples e entre as plantas, variando apenas o número de linhas no canteiro $(2,3$ e 4), o que ocasionou que o efeito da densidade de plantio, se devesse, também, a fatores de outra ordem - como a polinização, e não somente à penetração de radiação solar no interior do dossel.

Durante o período de cultivo, observou-se que, nas plantas cultivadas na densidade mais elevada, as flores ficavam menos expostas devido à elevada densidade de folhas (evidenciada pelo maior índice 
de área foliar - Tabela 3), dificultando a visitação das abelhas. Adicionalmente, a ventilação das plantas nessa densidade era reduzida, outro fator importante para a polinização na cultura. Como consequência, observouse maior abortamento das flores e menor número de frutos colhidos por planta, o que possivelmente levou à menor produção de massa fresca e seca de frutos (Tabela 1 e 2). Na maior densidade de plantio, o número de frutos por planta foi inferior às demais, totalizando 27,5 frutos, valor significativamente inferior aos obtidos na densidade de 3,51 e 5,26 plantas $\mathrm{m}^{-2}$ (35,4 e 35,1 frutos planta $^{-1}$ respectivamente).

É amplamente entendido que em hortaliças de fruto a partição de assimilados entre os órgãos da planta é, primeiramente, regulada pelos seus próprios drenos (frutos), visto que a força de fonte (fotossíntese) é de menor importância (Marcelis et al., 1998; Peil e Galvez, 2002; 2005). Assim, menor número de frutos induz, também, à menor acúmulo de massa seca no compartimento reprodutivo, devido a uma limitação em nível de drenos da planta, podendo proporcionar um maior acúmulo de fotoassimilados na fração vegetativa. Dessa forma, a maior densidade de plantio influenciou indiretamente o crescimento das plantas, reduzindo a força de drenos (menor número e massa de frutos por planta), o que, consequentemente, beneficiou o acúmulo de fotoassimilados nas folhas (Tabelas 2 e 3).

A maior densidade de plantio reduziu a contribuição proporcional dos frutos, o que é uma característica indesejada. Nas densidades, cuja contribuição proporcional de massa seca dos frutos foi superior (densidades de 3,51 e 5,26 plantas $\mathrm{m}^{-2}$ ), observase que os valores dos índices de colheita também foram superiores.

Para hortaliças de fruto, estes são os maiores drenos de fotoassimilados das plantas (AwANG e Atherton, 1995; Marcelis et al., 1998; Peil e Galvéz, 2002; ReEKIE et al., 2007; DuARTE et al., 2008; Paula et al., 2008). No presente trabalho, nas densidades de 3,51 e 5,26 plantas $\mathrm{m}^{-2}$, os frutos representaram a maior proporção de massa seca dentre os órgãos aéreos (frutos, folhas e coroa), caracterizando-se como maiores drenos de fotoassimilados. Todavia, na maior densidade, as folhas representaram, aproximadamente, $53 \%$ da massa seca total da parte aérea das plantas. Dessa forma, nessa densidade de plantio, as folhas caracterizaram-se como fonte e, ao mesmo tempo, como os maiores drenos de fotoassimilados das plantas.

Dentre os parâmetros fisiológicos mais utilizados na análise de crescimento das plantas, destaca-se o índice de área foliar, uma vez que a fotossíntese, processo responsável pelo fornecimento da energia necessária ao crescimento da planta, depende diretamente dele. Quanto mais rápido a cultura atingir o índice de área foliar crítico (a partir do qual não se observam aumentos significativos na quantidade de radiação solar absorvida pelo dossel) e, quanto mais tempo a área foliar permanecer ativa, maior será sua produtividade biológica. A densidade de plantas afeta tanto o valor máximo do índice de área foliar atingido pela cultura, quanto o período de tempo decorrido desde a emergência até a estabilização do crescimento do índice de área foliar e, consequentemente, da absorção da radiação solar incidente. A densidade de plantio ideal a ser empregada é aquela suficiente para atingir o índice de área foliar ótimo, a fim de interceptar o máximo de radiação solar útil à fotossíntese e, ao mesmo tempo, maximizar a fração da massa seca alocada para os frutos (MArcelis et. al., 1998). Nesse contexto, com maior densidade de plantio houve maior índice de área foliar, todavia reduziu a produção de massa seca de frutos (Tabela 2). Densidades de plantio muito elevadas promovem o sombreamento mútuo das plantas causado pelo excesso de folhas por unidade de área, reduzindo a absorção de radiação solar e o crescimento individual de cada planta. No presente trabalho, o alto índice de área foliar interferiu negativamente, até mesmo, na polinização das plantas, reduzindo o número de frutos por planta, acarretando menor produção de massa seca deste órgão.

O maior acúmulo de massa seca nas folhas das plantas da maior densidade de plantio ocasionou maior expansão foliar, não interferindo na espessura do limbo foliar, evidenciado pela semelhança dos tratamentos em relação à área foliar específica, que proporciona uma estimativa desse parâmetro. A razão de área foliar expressa a área foliar que está sendo utilizada para produzir um grama de massa seca (BENINCASA, 2003). Observou-se que a eficiência fotossintética das folhas foi reduzida nas plantas cultivadas na densidade de 7,02 plantas $\mathrm{m}^{-2}$, uma vez que houve menor produção de massa seca aérea por unidade de área foliar. Podese supor que o aumento do sombreamento mútuo das plantas nessa densidade de plantio pode ter sido fundamental para a obtenção desse resultado.

\section{CONCLUSÕES}

1. As cultivares de morangueiro Diamante e Aromas possuem padrões semelhantes de crescimento e de produtividade.

2. A densidade de 5,26 plantas $\mathrm{m}^{-2}$, com linhas triplas de cultivo favorece a produção e a partição de biomassa, bem como a produtividade de plantas de morangueiro das cultivares Diamante e Aromas em sistema de cultivo orgânico. 


\section{REFERÊNCIAS}

ALBREGTS, E.E. Influence of plant density on strawberry fruit production. Proceedings of the Florida State Horticultural Society, v.84, p.156-159, 1971.

ALBREGTS, E.E.; HOWARD, C.M. Plant density effects on strawberry fruit production. Proceedings of the Florida State Horticultural Society, v.86, p.116-118, 1973.

ANDRIOLO, J.L.; BONINI, J.V.; BOEMO, M.P. Acumulação de matéria seca e rendimento de frutos de morangueiro cultivado em substrato com diferentes soluções nutritivas. Horticultura Brasileira, v.20, p.24-27, 2002.

ANDRIOLO, J.L.; JANISCH, D.I.; SCHMITT, O.J.; VAZ, M.A.B.; CARDOSO, F.L.; ERPEN, L. Concentração da solução nutritiva no crescimento, na produtividade e na qualidade de frutas do morangueiro. Ciência Rural, v.39, p.684-690, 2009.

AWANG, Y.B.; ATHERTON, J.G. Growth and fruit responses of strawberry plants grown in rockwool to shading and salinity. Scientia Horticulturae, v.62, p.25-31, 1995.

BENINCASA, M.M.P. Análise de crescimento de plantas: Noções básicas. Jaboticabal: FCAV. 2003. 41p.

CASTRO, R.L.; CASALI, V.W.D.; BARRELLA, T.P.; SANTOS, R.H.S.; CRUZ, C.D. Produtividade de cultivares de morangueiro em sistema de cultivo orgânico. Horticultura Brasileira, v.21, p.227-230, 2003.

COMISSÃO DE QUÍMICA E FERTILIDADE DO SOLO - RS / SC. Manual de adubação e calagem para os Estados do Rio Grande do Sul e de Santa Catarina. $10^{a}$ ed. Porto Alegre: SBCS - Núcleo Regional Sul UFRGS, 2004. p.258-259.

CONTI, J.H.; MINAMI, K.; TAVARES, F.C.A. Produção e qualidade de frutos de morango em ensaios conduzidos em Atibaia e Piracicaba. Horticultura Brasileira, v. 20, p.10-17, 2002.

DIJKSTRA, J.; DE BRUIJN, J.; SCHOLTENS, A.; WIJSMULLER, J.M. Effects of planting distance and peat volume on strawberry production in bag and bucket culture. Acta Horticulturae, n.348, p.180-187, 1993.

DUARTE FILHO, J.; ANTUNES, L.E.C.; PÁDUA, J.G. de. Cultivares. Informe Agropecuário, v.28, p.20-23, 2007.

DUARTE, T.S.; PEIL, R.M.N.; MONTEZANO, E.M. Crescimento de frutos do meloeiro sob diferentes relações fonte:dreno. Horticultura Brasileira, v.26, p.342-347, 2008.

FERNANDES JÚNIOR, F.; FURLANI, P.R.; RIBEIRO, I.J.A.; CARVALHO, C.R.L. Produção de frutos e estolhos de morangueiro em diferentes sistemas de cultivo em ambiente protegido. Bragantia, v.61, p.25-34, 2002.

FREEMAN, B. Response of strawberry fruit yield to plant population density. Australian Journal of Experimental Agriculture and Animal Husbandry, v.21, p. 349-353, 1981.
LEGARD, D.E.; XIAO, C.L.; MERTELY, J.C.; CHANDLER; C.K. Effects of plant spacing and cultivar on incidence of Botrytis fruit rot in annual strawberry. Plant Disease, v.84, p.531-538, 2000.

LINSLEY-NOAKES, G.; WILKEN, L.; VILLIERS, de S. High density, vertical hydroponics growing system for strawberries. Acta Horticulturae, n.708, p.365-370, 2006.

LOSS, J.T.; CALVETE, E.O.; NITSCHE, R.; RAMBO, A.; NIENOW, A.A.; CECCHETTI, D. Desempenho de cultivares de morangueiro em dois sistemas de produção. In: CONGRESSO BRASILEIRO DE OLERICULTURA, 49., 2009, Águas de Lindóia. Anais... Brasília: ABH, 2009. p.1900-1906. (CD -ROM)

MADDEN, L.V.; BOUDREAU, M.A. Effect of strawberry density on the spread of anthracnose caused by Colletotrichum acutatum. Phytopathology, v.87, p.828-838, 1997.

MARCELIS, L.F.M.; HEUVELINK, E.; GOUDRIAAN, J. Modelling biomass production and yield of horticultural crops: a review. Scientia Horticulturae, v.74, p. 83-111, 1998.

MOTA, F.S.; BEIRSDORF, M.I.C.; ACOSTA, M.J. Estação Agroclimatológica de Pelotas: realizações e programa de trabalho. Pelotas: UFPEL, 1986.

PAPADOPOULOS, A.P.; ORMROD, D.P. Plant spacing effects on growth and development of greenhouse tomato. Canadian Journal of Plant Science. v.71, p.297-304, 1991.

PAULA, V.A.; MENDEZ, M.E.G.; SCHOFFEL, E.R.; PEIL, R.M.N.;RIBEIRO,D.S.;FRAGA,D.S.;ANDRADE,F.F.Produção e partição de massa seca da parte aérea do morangueiro cultivado em ambiente protegido sob adubação orgânica. In: CONGRESSO BRASILEIRO DE OLERICULTURA, 48.,2008, Maringá. Anais... Maringá: ABH, 2008. p.5931-5936 (CD ROM)

PEIL, R.M.N.; GALVÉZ, J.L. Growth and biomass allocation to the fruits in cucumber: effect of plant density and arrangement. Acta Horticulturae, n.588, p.75-80, 2002.

PEIL, R.M.N.; GALVÉZ, J.L. Reparto de materia seca como factor determinante de la producción de las hortalizas de fruto cultivadas em invernadero. Revista Brasileira de Agrociências, v.11, p.5-11, 2005.

PEREIRA, A.R. Competição intra-específica entre plantas cultivadas. O Agronômico, v. 41, p.5-11, 1989.

PEREIRA, A.R.; MACHADO, E.C. Análise quantitativa do crescimento de comunidade de vegetais. Campinas: Instituto Agronômico, 1987. 33p. (Boletim técnico)

PIRES, R.C.M.; FOLEGATTI, M.V.; PASSOS, F.A.; ARRUDA, F.B.; SAKAI, E. Vegetative growth and yield of strawberry under irrigation and soil mulches for different cultivation environments. Scientia Agricola, v.63, p.471-425, 2006. 
REEKIE, J.Y.; STRUIK, P.C.; HICKLENTON, P.R.; DUVAL, J.R. Dry matter partitioning in a nursery and a plasticulture fruit field of strawberry cultivars 'Sweet Charlie' and 'Camarosa' as affected by prohexadione-calcium and partial leaf removal. European Journal of Horticultural Science, v.72, p.122-129, 2007.

SCHIEDECK, G.; GONÇALVES, M. de M.; SCHWENGBER, J.E. Minhocultura e produção de húmus para a agricultura familiar. Pelotas: Embrapa Clima Temperado, 2006. (Circular Técnica 57)
VILLELA JÚNIOR, L.V.E.; ARAÚJO, J.A.C.; FACTOR, T.L. Análise do resfriamento da solução nutritiva para cultivo hidropônico do morangueiro. Engenharia Agrícola, v.24, p.338-346, 2004.

VIRMOND, M.F.R.; RESENDE, J.T.V. de. Produtividade e teor de sólidos solúveis totais em frutos de morango sob diferentes ambientes de cultivo. Revista Eletrônica Lato Sensu, v.1, p.6269, 2006. 